\title{
IDENTIFIKASI MORFOLOGI KEPADATAN SPECIES LALAT DAN UPAYA PENGENDALIAN DI PUSAT PASAR BERASTAGI KABUPATEN KARO TAHUN 2019
}

\author{
Jernita Sinaga ${ }^{1}$, Likasi Emita ${ }^{2}$ \\ Poltekkes Kemenkes Medan ${ }^{12}$ \\ e-mail: 2likasiemitasebayang@gmail.com
}

\begin{abstract}
Identification of species of flies can see the characteristics of the body shape of flies by looking at organs identified by using a microscope and identification key book of adult fly species using Borror identification keys, and literature search by examining books and articles about flies, guidelines for entomological surveys. The body offlies is usually short, small and slender life flies are very adaptable to the surrounding air. Knowing the fly's morphology and measuring the density of flies by identifying the species of flies in this study is one of the efforts to determine the level of density and population distribution of fly species in the Berastagi market. The fly is one of the insects of the Order listed which is a member of the Hexapoda class or the insect has the largest number of genera and species which covers 60-70\% of all Anthropod species or 60,000 - 100,000 species of flies.
\end{abstract}

Keywords: Flies sp, Morphology, Identification.

\begin{abstract}
ABSTRAK
Identifikasi spesies lalat dapat melihat ciri-ciri bentuk tubuh lalat dengan melihat organ yang diidentifikasi dengan menggunakan mikroskop dan buku kunci identifikasi spesies lalat dewasa menggunakan kunci identifikasi Borror, dan penelusuran literatur dengan memeriksa buku dan artikel tentang lalat, pedoman survei entomologi. Tubuh lalat biasanya pendek, kecil dan ramping hidup lalat sangat mudah beradaptasi dengan udara sekitarnya. Mengetahui morfologi lalat dan mengukur kepadatan lalat dengan mengidentifikasi jenis lalat dalam penelitian ini merupakan salah satu upaya untuk mengetahui tingkat kepadatan dan sebaran populasi jenis lalat di pasar Berastagi. Lalat merupakan salah satu serangga dari ordo yang terdaftar yang merupakan anggota kelas Hexapoda atau serangga yang memiliki jumlah marga dan spesies terbanyak yaitu mencakup 60$70 \%$ dari seluruh spesies Antropoda atau 60.000 - 100.000 spesies lalat.
\end{abstract}

Kata Kunci : Lalat sp, Morfologi, Identifikasi.

\section{PENDAHULUAN}

Lalat merupakan salah satu insekta Ordo diptera yang merupakan anggota kelas Hexapoda atau insekta mempunyai jumlah genus dan spesies yang terbesar yaitu mencakup 60-70 \% dari seluruh spesies Anthropoda. Lalat dapat mengganggu kenyamanan hidup manusia, menyerang dan melukai hospesnya (manusia atau hewan) serta menularkan penyakit diantaranya demam typhus, paratyphus, disentri, kholera dan sebagainya.
Lalat merupakan salah satu vektor perantara penyakit yang populasinya banyak ditemukan di tempat-tempat umum seperti pasar, rumh sakit, rumah makan, dll di sekitar masyarakat maupun dipemukiman. Lalat juga menimbulkan gangguan estetika dan mengganggu manusia secara psikologis. Lalat merupakan serangga yang tersebar luas di seluruh dunia. Bagian tubuh lalat yang dapat berperan sebagai alat penularan penyakit antara lain yaitu kaki, sayap, bulu pada tubuh, faeces serta muntahannya (Ditjen PPM dan PLP 1991, h.1). Lalat sangat tertarik pada baubauan yang busuk, tumpukan sampah yang basah, sayuran serta sisa-sisa potongan pada penjualan daging. 
Pasar merupakan salah satu tempattempat umum sebagai tempat orang-orang berkumpul untuk melakukan kegiatan jual beli barang-barang kebutuhan hidup sehari-hari. Sebagai tempat umum, sangatlah perlu adanya pengawasan terhadap sanitasi pasar. Pengawasan dilakukan untuk mencegah terjadinya penularan penyakit, baik antara pedagang dengan pembeli, pedagang dengan pedagang ataupun antara pembeli dengan pembeli. Salah satu bentuk pengawasan sanitasi pasar adalah dengan melakukan pengukuran kepadatan lalat dan identifikasi jenisnya serta melakukan upaya pengendalian lalat. Keberadaan lalat di pasar tidak terlepas dari adanya kegiatan jual beli yang senantiasa menghasilkan sampah dan bau-bauan kas, Menurut Masyuda (2017) mengatakan bahwa adanya kehidupan lalat dalam masyarakat merupakan bukti rendahnya tingkat kondisi sanitasi.

Berastagi terdapat pasar tradisional terbesar yaitu pasar Berastagi yang setiap hari ramai dikunjungi oleh segenap lapisan masyarakat. Ditinjau dari lokasinya, Pasar Berastagi terletak di pusat pasar lokasinya lebih ramai dan strategis. Demikian pula dengan sistem pengelolaannya, Sebagai pasar tradisional Berastagi tidak terlepas dari keberadaan lalat. Berdasarkan survei awal, ditemukan banyak lalat pada tempat-tempat tertentu seperti tempat penjualan daging, tempat penjualan ikan basah, tempat penjualan ayam potong, tempat penjualan sayuran, tempat penjualan ikan asin, tempat penjualan buah-buahan, tempat penjualan warung makanan yang telah dimasak serta tempat sampah sementara (TPSS).

\section{METODE}

Jenis penelitian ini adalah Explatary Research bersifat deskriptif yaitu melakukan pemeriksaan laboratorium dengan tehnik identifikasi struktur anatomi species lalat,dan melakukan pengukuran parameter lingkungan (suhu, kelembaban, pencahayaan) secara langsung pada titik pengambilan sampel kepadatan lalat dan upaya pengendalian vektor lalat di lokasi titik pengambilan sampel penelitian Pusat Pasar Berastagi Kabupaten Karo. Data diperoleh dengan melakukan pengukuran angka kepadatan lalat dilokasi yang terpilih sebagai sampel, dengan menggunakan Fly-grill dan Hand counter (untuk menghitung lalat yang hinggap di flygrill) serta thermo meter dan hygrometer untuk pengukuran suhu dan kelembaban, lux meter untuk pengukuran pencahayaan.

Penelitian mulai dari tahap persiapan sampai penyelesaian dilaksanakan selama sembilan bulan (Januari - Oktober 2019). Penelitian dilakukan di Pusat Pasar Berastagi Kabupaten Karo. Subyek penelitian ini adalah kepadatan dan jenis lalat di Pusat Pasar Pasar Berastagi Kabupaten Karo. Sampel penelitian dilakukan di tempat penjualan daging, ikan basah, ayam potong, sayuran, ikan asin, buahbuahan,warung makan, dan tempat pembuangan sampah sementara (TPSS). Pengumpulan data dilakukan dengan cara wawancara, pengamatan dan pengukuran kepadatan lalat, pencahayaan, suhu, dan kelembaban.

\section{HASIL DAN PEMBAHASAN}

Distribusi Kepadatan Vektor species lalat dengan tehnik identifikasi lalat berdasarkan titik pengambilan sampel

Identifikasi di laksanakan di Laboratorium Poltekkes Medan Jurusan Kesehatan Lingkungan setelah melakukan penangkapan dan pengukuran kepadatan lalat di lokasi penelitian dan lalat yang tertangkap di bawa ke laboratorium. Jumlah total populasi lalat yang berhasil ditangkap dan diidentifikasi dalam penelitian ini ada 446 ekor. Jumlah tersebut setelah proses identifikasi menggunakan mikroskop dan buku kunci identifikasi lalat, lalat yang paling banyak ditemukan adalah lalat rumah (Muscadomestica) 297 ekor dan yang paling sedikit ditemukan adalah, lalat kuda (Tabanidae) 1 ekor dan lalat pasir (Spriverpe Lunulata) 1 ekor, dan beberapa jenis-jenis lalat diantaranya adalah lalat daging (Sarckopaga) 75 ekor, lalat, lalat hijau (calliphora Vomitoria) 54 ekor, lalat buah Drosohila Species 12 ekor, lalat hitam (Hermatialilucea) 6 ekor. Hasilt dilihat pada 
Distribusi Perbedaan Populasi Vektor Species Lalat berdasarkan Pencahayaan Pada Titik Pengambilan Sampel

Berdasarkan hasil pengukuran kepadatan dan penangkapan dari setiap titik dilokasi ditemukan beberapa jeni-jenis vektor lalat dengan menggunakan fly grill di lokasi penelitian dengan rata-rata pencahayaan yang di ukur langsung pada saat meletakkan fly grill menggunakan lux meter dengan pencahayaan $>400^{\circ} \mathrm{Lx}$ merupakan jumlah lalat yang terbanyak dengan total jumlah lalat 227 ekor didapat berbagai jenis lalat yang diantaranya adalah lalat rumah (Muscadomestica) 155 ekor, lalat daging (Sarckopaga) 35 ekor, lalat, lalat hijau (calliphora Vomitoria) 34 ekor, lalat buah (Drosohila) 2 ekor, lalat kuda ( Tabanidae) 1 ekor, Jumlah vector species lalat terendah dengan pencahayaan $<200^{\circ} \mathrm{Lx}$ ditemukan 109 ekor lalat dengan rincian lalat rumah (Muscadomestica) 67 ekor, lalat daging (Sarckopaga) 31 ekor, lalat hijau (Calliphora Vomitoria) 10 ekor, lalat pasir (Spriverp Lanulata) 1 ekor. Hasil dapat dilihat pada Tabel 5

Tabel 5. Distribusi Populasi Lalat Berdasarkan Pencahayaan

\begin{tabular}{|c|c|c|c|c|}
\hline \multirow{2}{*}{$\begin{array}{c}\text { Pencaha } \\
\text { yaan } \\
\left({ }^{0} \mathbf{L x}\right)\end{array}$} & \multicolumn{4}{|c|}{ Spesies Lalat yang ditemukan } \\
\hline & $\begin{array}{c}\text { Lalat } \\
\text { Dagin } \\
\text { g } \\
\text { (Sarc } \\
\text { hopag } \\
\text { a) }\end{array}$ & $\begin{array}{c}\text { Lalat } \\
\text { Rumah } \\
\text { Musca } \\
\text { domestic } \\
\text { a) }\end{array}$ & $\begin{array}{c}\text { Lalat } \\
\text { Hijau } \\
\text { (Lucilia } \\
\text { Sericata } \\
\text { ) }\end{array}$ & $\begin{array}{c}\text { Lalat } \\
\text { Buah } \\
\text { (Tep } \\
\text { hritid } \\
\text { ae }\end{array}$ \\
\hline$<200$ & 31 & 67 & 10 & 0 \\
\hline $200-400$ & 9 & 75 & 10 & 10 \\
\hline$>400$ & 35 & 155 & 34 & 2 \\
\hline Total & 75 & 297 & 54 & 12 \\
\hline
\end{tabular}

Distribusi kepadatan vektor species lalat dengan tehnik identifikasi lalat berdasarkan titik pengambilan sampel.

Identifikasi Species lalat dapat melihat ciri-ciri bentuk tubuh lalat dengan melihat organ tubuh yang di identifikasi dengan mengunakan mikroskop dan buku kunci identifikasi spesies lalat dewasa menggunakan kunci identifikasi Borror, serta penelusuran literatur dengan menelaah buku dan artikel tentang lalat, pedoman survei entomologi.

Mengetahui morfologi lalat dengan Pengukuran kepadatan lalat dengan mengidentifikasi species lalat dalam penelitian ini merupakan salah satu upaya untuk mengetahui tingkat kepadatan dan penyebaran populasi spesies lalat di pasar Berastagi. Pasar Berastagi Kabupaten Karo ditemukan Jumlah total populasi lalat yang berhasil ditangkap dan diidentifikasi dalam penelitian ini ada 446 ekor. Jumlah tersebut setelah proses identifikasi menggunakan mikroskop dan buku kunci identifikasi lalat, lalat yang paling banyak ditemukan adalah lalat rumah (Muscadomestica) 297 ekor dan yang paling sedikit ditemukan adalah, lalat kuda (Tabanidae) 1 ekor dan lalat pasir (Spriverpe Lunulata) 1 ekor, dan beberapa jenis-jenis lalat diantaranya adalah lalat daging (Sarckopaga) 75 ekor, lalat, lalat hijau (calliphora Vomitoria) 54 ekor, lalat buah Drosohila Species 12 ekor, lalat hitam (Hermatialilucea) 6 ekor. Hasil penelitian ini dipengaruhi dengan prevalensi data observasi lapangan tentang sanitasi pasar di pasar Berastagi dan juga dipengaruhin oleh keadaan lokasi ataupun keadaan suhu, kelembaban udara yang rendah dan pencahłyaan yang kurang. Perkembangbiakan species lalat

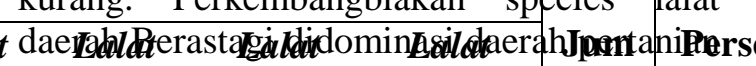

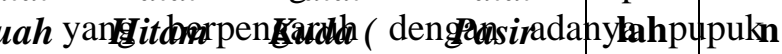

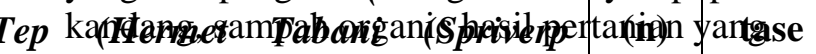
itid pada ia umumngtae dapaLumanjadi temp $\boldsymbol{e}$ pefkimdeangbiakan dari pada lalat. Pengukuran terhadap populasi lalat dewa@g lebih tepat dan bis diandall $69 n$ davi,43 10 pada rengukuraropopulasi lorva lalat 10epke\&,44

2001). Sebagai ipterpretasi 7 hasi, 89
pengukuran indek populasi falat jugq4ergunf00 untuk menentukan tindakan pengendalian yang akan dilakukan. Indeks populasi lalat terbagi menjadi (Depkes RI, 2001), dengan pengukuran bahwa 0 - 2 ekor dinyatakan rendah atau tidak menjadi masalah, 3 - 5 ekor dinyatakan sedang atau perlu tindakan pengendalian terhadap tempat perkembangbiakan lalat, 6 - 20 ekor dinyatakan tinggi atau populasi cukup padat, perlu pengamanan terhadap tempat-tempat perindukan lalat dan bila mungkin direncanakan upaya pengendalian dan $\geq 21$ 
ekor sangat tinggi sehingga perlu dilakukan pengamanan terhadap tempat - tempat perkembangbiakan lalat dan pengendalian lalat. Pengukuran kepadatan lalat dengan menggunakan fly grill di lokasi penelitian, dengan pengukuran dititik $10 \mathrm{~m}, 20 \mathrm{~m}$ dan 50 meter dari setiap jenis pedagan yang di penjualan maka rata-rata distribusi kepadatan lalat yang paling padat ditemukan pada pedangan daging dengan rata-rata kepadatan lalat 11 tinggi) dan yang terendah ditemukan pada pedangan sayuran dengan rata-rata 2 (kepadatan lalat rendah) dari setiap pedangan yang dilihat distribusi tiap pedangan adalah pedagang ikan basah 3 (sedang), padangan ayam potong 4 (sedang), pedagan buahbuahan 3 (sedang), pedagang ikan asin 9 (tinggi) dan pada pedagan makanan 4 (sedang), namun dilihat dari tempat pembuangan sampah sementara (TPSS) yang ada di sekitar pasar masih lebih tinggi dengan rata - rata 15 (Tinggi)

Pedagan daging dengan kepadatan 11 dikategorikan tinggi atau populasi cukup padat, perlu pengamanan terhadap tempattempat perindukan lalat dan bila mungkin direncanakan upaya pengendalian. Pada pedagang sayuran dengan rata-rata 2 (kepadatan lalat rendah) dengan pengukuran bahwa 0 - 2 ekor dinyatakan rendah atau tidak menjadi masalah namun harus tetap menjaga kebersihan dan dilakukan pengendalian.

Kebanyakan orang sudah mengetahui dan mengerti bahwa lalat adalah pembawa penyakit. Kenyataanya masih banyak kita temukan masyarakat tetap saja ada yang tidak perduli dan tetap memakan makanan yang telah dihinggapi lalat. Makanan yang telah dihinggapi lalat pembawa penyakit dan hewan yang suka hinggap di tempat kotor akan dapat menyebabkan penyakit bagi orang yang mengkonsumsinya. Badan Kesehatan Dunia (WHO) juga menyatakan bahwa ada banyak penyakit yang disebabkan oleh makanan dihinggapi lalat, seperti disentri, diare, demam tifoid atau tipes, kolera, infeksi mata, Infeksi kulit.

Suhu udara yang rendah menjadi faktor yang meningkatkan laju pertumbuhan lalat. Sebaliknya, suhu yang lebih tinggi dapat menghambat laju pertumbuhan lalat. Menurut Ditjen PPM dan PLP (1991, h.4) pada musim panas lalat bertahan 2 - 4 minggu, sedangkan pada musim dingin bisa mencapai 70 hari. Menurut Ditjen PPM dan PLP (1991, h. 4) lalat mulai terbang pada temperatur $15^{\circ} \mathrm{C}$ dan aktivitas optimumnya pada temperatur $21^{\circ} \mathrm{C}$. Pada temperatur dibawah $7,5^{\circ} \mathrm{C}$ tidak aktif, diatas $45^{\circ} \mathrm{C}$ terjadi kematian pada lalat.

Kota Berastagi sangat dikenal dengan daerah suhu rendah yang sangat cocok untuk perkembangbiakan lalat ini terbukti dari hasil pengukuran kepadatan dan penangkapan dari setiap titik dilokasi ditemukan beberapa jenijenis vektor species lalat dengan menggunakan fly grill di lokasi penelitian dengan pengukuran rata-rata suhu yang di ukur langsung pada saat meletakkan fly grill menggunakan thermometer suhu dengan suhu $<25^{\circ} \mathrm{C}$ merupakan jumlah lalat yang terbanyak dengan total jumlah lalat 271 ekor didapat berbagai jenis lalat yang diantaranya adalah lalat rumah (Muscadomestica) 197 ekor, lalat daging (Sarckopaga) 31 ekor, lalat, lalat hijau (calliphora Vomitoria) 25 ekor, lalat buah ( Drosohila)12 ekor, lalat hitam (Hermatialilucea) 6 ekor.

Namun tidak menutup kemungkinan pada suhu $>30^{\circ} \mathrm{C}$ di pasar Berastagi ditemukan species lalat 59 ekor dengan rincian lalat rumah (Muscadomestica) 26 ekor, lalat daging (Sarckopaga) 30 ekor, lalat, lalat hijau (Calliphora Vomitoria) 2 ekor, lalat pasir (Spriverpa Lunulata) 1 ekor, yang dapat berpengaruh dengan adanya tempat yang memungkinkan perkembangbiakan lalat dengan adanya sampah organik dan yang lainnya.

sekaligus sarang untuk berkembang biak bagi lalat. Tempatkan makanan pada wadah yang bisa ditutup rapat. Tindakan ini akan mencegah makanan terkontaminasi dan tetap bersih. WHO juga menganjurkan untuk selalu membuang sampah pada tempatnya dan usahakan agar tempat sampah di pasar berastagi selalu tertutup dan terdapat tempat sampah sesuai dengan jenis sampah. Jadi, lalat tidak berkesempatan untuk hinggap di atasnya, pihak dinas pasar dan dnas kesehatan terkait agar melakukan penyuluhan untuk pembuangan sampah yang memenuhi syarat tehnik utama dalam pengendalian lalat.

\section{KESIMPULAN}


Pasar Berastagi Kabupaten Karo ditemukan Jumlah total populasi lalat yang berhasil ditangkap dan diidentifikasi dalam penelitian ini ada 446 ekor. Jumlah tersebut setelah proses identifikasi menggunakan mikroskop dan buku kunci identifikasi lalat, lalat yang paling banyak ditemukan adalah lalat rumah (Muscadomestica) 297 ekor dan yang paling sedikit ditemukan adalah, lalat kuda (Tabanidae) 1 ekor dan lalat pasir (Spriverpe Lunulata) 1 ekor. Kelembaban optimal yang diperlukan untuk pertumbuhan lalat adalah berkisar antara $60^{\circ} \mathrm{F}-90^{\circ} \mathrm{F}$ dan tidak mendukung jika kelembaban udara $<60^{\circ} \mathrm{F}$ atau $>90^{\circ} \mathrm{F}$. Rata-rata hasil yang didapatkan $<60^{\circ} \mathrm{F}$ merupakan jumlah lalat yang terbanyak dengan total jumlah lalat 226 ekor. Tindakan pengendalian lalat dapat dilakukan dengan perbaikan hygiene dan sanitasi lingkungan yaitu dengan cara mengurangi dan menghilangkan tempattempat perindukan lalat dengan metode pembuangan sampah dari mulai pengumpulan, pengangkutan, dan pembuangan sampah yang dikelola dengan baik dapat menghilangkan media perindukan lalat.

\section{DAFTAR PUSTAKA}

Adnyana E, I Made. 1985. Pemberantasan Serangga Penyebar Penyaki t Tanaman Liar dan Penggunaan Pestisida, Denpasar : SPPH

Indonesia, Depkes RI. 1991. Petunjuk Teknis Tentang Pemberantasan Lalat, Jakarta :

Depkes RI .1993. Persyaratan Kesehatan Lingkungan dan Tempattempat Umum, Jakarta :
Depkes RI . 200001 . Pe $d$ oman Teknis

Pengendalian Lalat, Jakarta : Depkes RI

Erza Nur Afrilia Hubungan Kondisi Rumah dan Kepadatan Lalat di Sekitar Tempat Pembuangan Akhir Sampah Departemen Kesehatan Lingkungan, Fakultas Kesehatan Masyarakat, Universitas Indonesia, Indonesia 2017

Iskandar. 1985. Pemberantasan Serangga dan Binatang Pengganggu, Jakarta : Pusat Pendidi kan Tenaga Kesehatan

Keputusan Direktur Jenderal Pemberantasan Penyakit Menular dan Penyehatan Lingkungan Pemukiman Nomor HK.00.06.6.44 Tanggal 18 Februari 1993 Tentang Persyaratan Petunjuk Teknis Tata Cara Penyehatan Lingkungan Rumah Sakit

Masyhuda, Retno Hestiningsih, Rully Rahadian ( 2017) Survei Kepadatan Lalat di Tempat Pembuangan Akhir (TPA) Sampah Jatinarang Bagian Epidemiologi dan Penyakit Tropik, Fakultas Kesehatan Masyarakat Universitas Diponegoro

Saruji dan Didik. 1982. Pengelolaan Sampah, Surabaya: Instalasi Penerbit Akademi Penilik Kesehatan Surabaya

Sudarmono dan Pratiwi Puji Lestari. 1992. Pest Control Indonesia, Jakarta, IPPHAMI

Suparlan. 1981. Pedoman Pengawasan Sanitasi Tempat-tempat Umum, Surabaya: Instalasi Penerbit Akademi Penilik Kesehatan Surabaya

Wasito dan Sidik. 1979. Sanitasi Pembuangan Sampah Dalam Masyarakat Perkotaan, Jakarta: Akademi Penilik Kesehatan. 